\title{
Increased Fertility Rate Improves House Hold Utility, Despite Reducing the Wage Rate: The Burden of Long-Term Care Services
}

\author{
Masatoshi Jinno \\ Faculty of Economics, Toyo University, Tokyo, Japan \\ Email: jinno@toyo.jp
}

Received 7 April 2014; revised 12 May 2014; accepted 20 May 2014

Copyright (C) 2014 by author and Scientific Research Publishing Inc.

This work is licensed under the Creative Commons Attribution International License (CC BY). http://creativecommons.org/licenses/by/4.0/

\begin{abstract}
In many developed countries, fertility rates are in decline and longevity is increasing. While greater longevity is cause for celebration, a growing elderly population increases the overall demand for expanded social security programs, particularly those pertaining to long-term care services. By considering and measuring the care burden per capita, we show that an increase in the fertility rate can improve household utility, even though it reduces the wage rate. The findings of this analysis imply that improvements in the fertility rate are desirable, as it eases burdens relating to long-term care services, as well as those relating to public pension plans.
\end{abstract}

\section{Keywords}

Eldercare, Long-Term Care Services, Exogenous Fertility Rate, Social Security

\section{Introduction}

In many developed countries, fertility rates are declining and longevity is increasing. On the face of it, greater longevity is cause for celebration; however, a growing elderly population also increases demand for expanded social security programs, particularly those pertaining to long-term care services. It is very important that society, at the very least, meets the demand for minimum necessary long-term care services for the elderly.

Let us take a look at actual data showing what and how much individuals consume, by age, in Japan and the United States, two highly developed countries. Figure 1(a) shows expenditures on goods $i$ consumed by those in age group $j$, compared to people in their forties in Japan; these data are from the 2009 Household Survey con- 


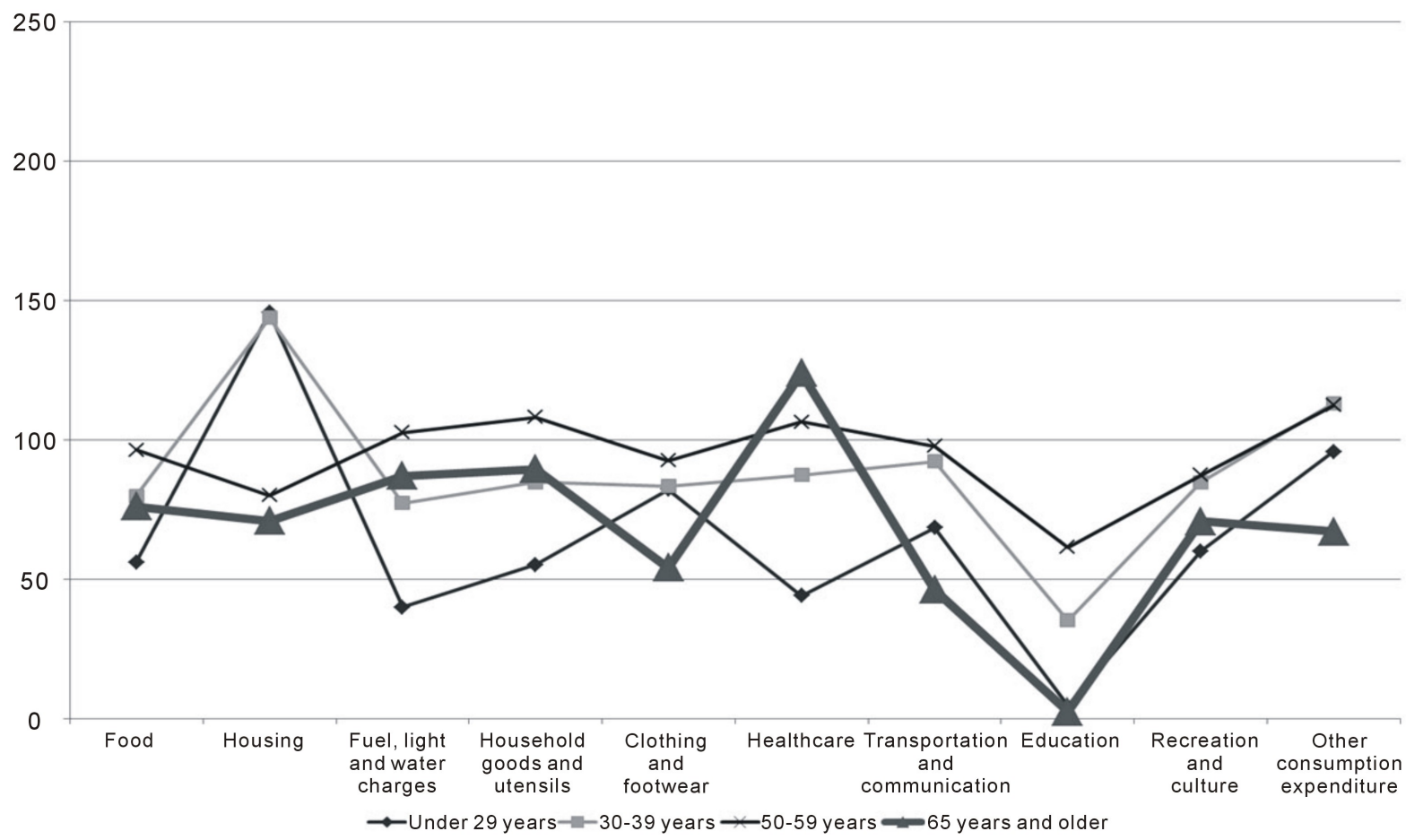

(a)

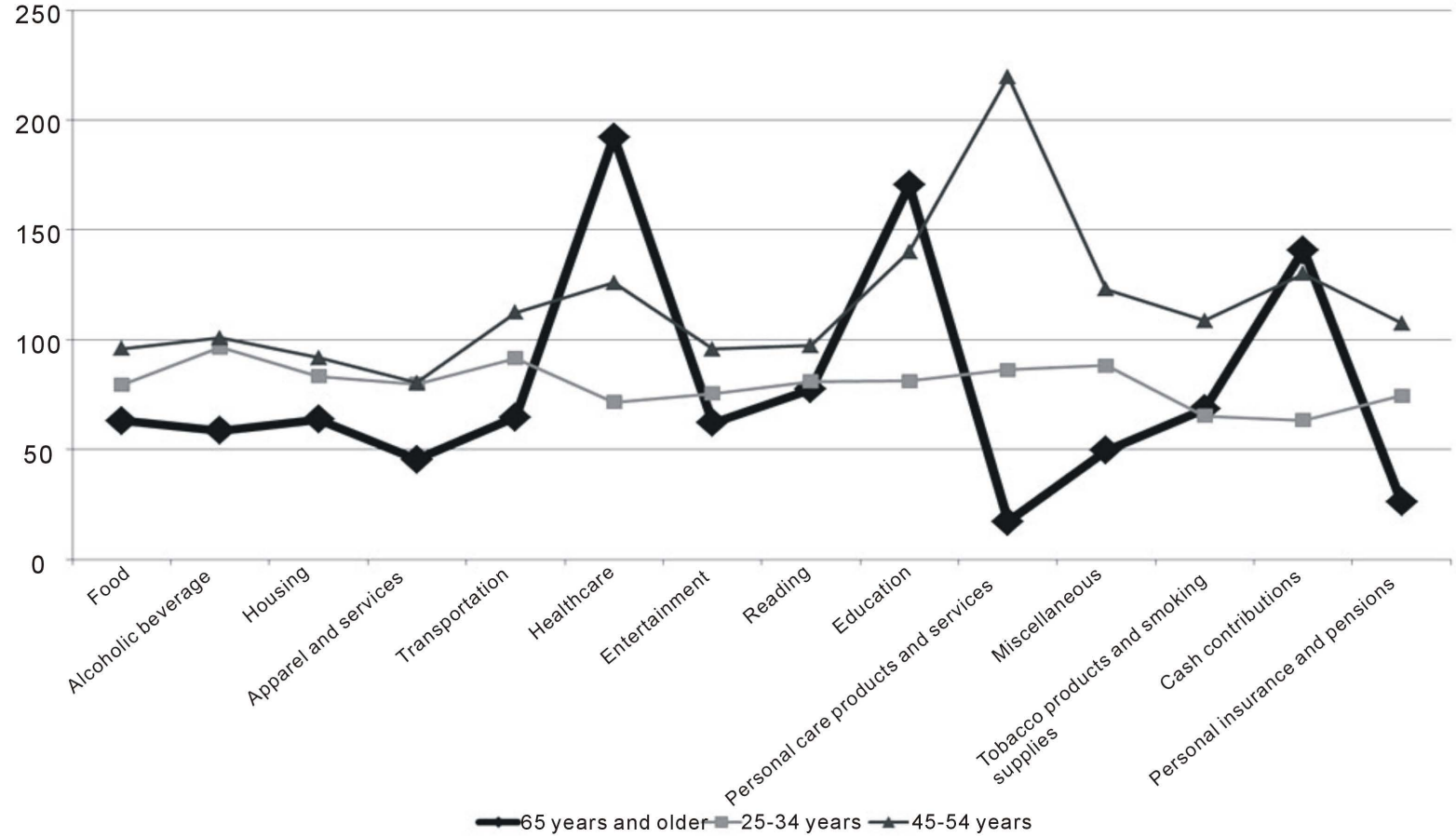

(b)

Figure 1. (a) Average expenditures in Japan, by age division, Note. Values are calculated as $\left(x_{j}^{i} / x_{40}^{i}\right) \times 100$, where $x_{j}^{i}$ is the expenditure of the age division $j$ for good $i$. Thus, if the value is over (below) 100, it is more (less) than that of individuals in their forties in Japan; (b): Average expenditures in the United States, by age division, Note. Values are calculated as $\left(x_{j}^{i} / x_{40}^{i}\right) \times 100$, where $x_{j}^{i}$ is the expenditure of the age division $j$ for good $i$. Thus, if the value is over (below) 100 , it is more (less) than that of individuals aged 35 - 44 years in the United States. 
ducted by Japan's Ministry of Internal Affairs and Communications. Figure 1(b) shows goods expenditures by age group, compared to 35 - 44-year-olds in the United States; these US data are derived from the 2009 Consumer Expenditure Survey conducted by the US Bureau of Labor Statistics.

These figures show that in both Japan and the United States, elderly people spend more on healthcare services than those in any other age group. For all goods except those in the clothing and footwear, transportation and communication, and education categories, consumption by elderly people in Japan is somewhat lower than but approximating that of people in their forties. In the United States, elderly people spend less money than 35 44-year-olds on apparel and services, education, tobacco products and smoking supplies, and personal insurance and pensions, but more than 35 - 44-year-olds on reading and cash contributions, and about the same on other goods.

Thus, when considering the problems posed by an aging population, it is very important for us to bear in mind differences between elderly people and the general population, in terms of the kinds of things they consume. Groezen, Meijdam, and Verbon [1]-[3] consider such differences, and assume that younger people consume capital-intensive commodities-which are produced with capital and labor-while elderly people consume only or relatively more labor-intensive services, which are produced with only labor. In their 2005 study, Groezen, Meijdam, and Verbon analyze the relationship between aging and economic growth. They later analyzed social security reform Groezen, Meijdam, and Verbon [2], and show that in a model involving a service sector, golden-rule capital stock is lower and dynamic inefficiency is more likely to occur than in a conventional one-sector model Groezen, Meijdam, and Verbon [3]. These studies consider endogenous re-allocation in the labor market to be a result of an increase in the supply of long-term care services, while assuming that elderly people can purchase as many long-term care services as they like.

However, not all elderly people can purchase sufficient long-term care services; economically disadvantaged elderly people who cannot save enough money to buy the services they need are forced to depend on government services. A full $90 \%$ of spending in the elderly nursing system in Japan is financed not just by insurance premiums paid by individuals over 40 years of age, but also by public funds from the national and local governments; users are charged for only $10 \%$ of the costs. Even so, because their savings cannot adequately cover expenses in their old age, many elderly people cannot purchase even the most essential of long-term care services (hereafter, "minimum necessary long-term care services”). Many believe that for these individuals to receive the minimum necessary long-term care services, the government should finance all related costs by using tax monies.

The provision of minimum necessary long-term care services requires the hiring of a sufficient number of long-term care workers. Long-term care workers must receive wages equal to those of workers in the business sector, because if the wages of long-term care workers are lower, no workers will choose to work in the longterm care sector. Thus, the government must work to make the wages of long-term care workers on par with those of business workers, by using tax-rate adjustments-just to provide elderly individuals with minimum necessary long-term care services. This, however, increases the tax burden on the working generation, in a society in which the number of children (and therefore the number of future caregivers and taxpayers) is decreasing.

As the number of children in a society increases, the per-capita tax burden drops; however, wage rates decrease, as does the capital-labor ratio. The combination of these two factors prompts us to ask whether there is a case in which, although an increase in the number of children lowers the average wages, it also decreases the per-capita burden of long-term care services, such that there is an overall improvement in the utility level. Furthermore, since an increase in the number of children reduces the per-capita tax burden-thus allowing individuals to increase their amounts of consumption-could this improve the utility level? The present study aims to explore these possibilities by using a simple overlapping generation model and considering fully the current, relevant issues.

A considerable body of literature relates to the care industry. Scholars such as Sandmo [4], Kleven et al. [5], and Yoshida and Yuki [6] analyzed the use of an optimal tax rate to provide funds for care services. In particular, Yoshida and Yuki [6] incorporate Samuelson's [7] consumption - loan model in their analysis of the optimal tax rate for care services. Galasso and Profeta [8] show that in terms of the economy, an aging society increases social security rates in relation to gross domestic product. Bethencourt and Galasso [9] further point out, on the basis of voting behavior, the complementary relationship between healthcare and social security.

Nevertheless, although many scholars have analyzed the problems inherent in the care industry, few other than Groezen, Meijdam, and Verbon [1]-[3] have investigated the role of the labor market. Like Groezen, Meijdam, and Verbon [1]-[3], the current study considers a two-sector model in which minimum necessary long-term 
care services are provided by the government, through the use of tax monies. Here, we analyze the effects of an increase in the number of children on the utility of households, when the wage rates of care workers are equivalent to those of business workers and there are enough care workers to provide those minimum necessary longterm care services.

The remainder of this paper is organized as follows. The model and a numerical example are presented in Section 2, and Section 3 summarizes our discussion and presents topics that require further study.

\section{The Model}

In this section, we develop an overlapping generational model. Here, it is assumed that the lifetime of a household is divided into three periods: a youth period, a working period, and a retirement period. After some uncontrollable amount of consumption in the first period of life, in the second period, households of generation $t$ work; bear $n$ children, given exogenously; consume a single all-purpose good; and save for retirement. In the third period, households only consume their retirement savings. The population transition between generations is $N_{t}=n N_{t-1} . N_{t}$ is the population of the $t^{\text {th }}$ generation. Elderly households (postretirement) inevitably need $h \in(0, n)$ long-term care workers to provide the minimum necessary long-term care services ${ }^{1}$. The total number of required long-term care workers, $H_{t}$, is $H_{t}=h N_{t-1}$. Some households in generation $t$ are employed as workers in competitive firms, and others are employed as long-term care workers. The total number of workers in firms, $L_{t}$, is $L_{t} L_{t}=N_{t}-H_{t}$. By substituting the population transition and the total number of required long-term care workers into the total number of workers in the firm, the number of workers in firms becomes $L_{t}=(n-h) N_{t-1}$.

Firms produce consumption goods. In each period, the capital stock is the sum of households' savings in the preceding period: $K_{t+1}=\bar{s}_{t} N_{t}$, where $\overline{s_{t}}$ is the average savings. (Note that variables bearing the notation are average values.) The capital stock lasts for only one period and has zero scrap value in the subsequent period. The initial capital stock ( $K_{0}$ ), which belongs to $N_{-1}$ households, is given to those who are elderly in period 0 . Each of them owns $\bar{s}_{-1}=K_{0} / N_{-1}$.

In each period, the Cobb-Douglas technology is employed for production, using two inputs: physical capital $K_{t}$ and labor $L_{t}$. Moreover, $Y_{t}=K_{t}^{\alpha_{1}} L_{t}^{\alpha_{2}}$, such that we have $\left(1+r_{t}\right)=\alpha_{1} Y_{t} / K_{t}$ and $w_{t}^{L}=\alpha_{2} Y_{t} / L_{t}$. Note that $\alpha_{1}+\alpha_{2}=1$. In addition, $r_{t}$ is the interest rate, and $w_{t}^{L}$ is the wage rate of workers in firms. Perfect competition in the factor markets ensures that, in equilibrium, the return from savings and wage per worker are equal to the respective marginal products.

The government imposes a care tax $\tau_{t}$ on households, which is used to pay care workers and is divided equally them. The budget constraint for this system is $w_{t}^{H} H_{t}=\tau_{t}\left(w_{t}^{H} H_{t}+w_{t}^{L} L_{t}\right) . w_{t}^{H}$ is the wage rate of care workers; the government adjusts the care-tax rate to ensure that the wage rate of care workers is comparable to that of firm workers. The adjusted care tax endogenously becomes $\tau_{t}=\tau_{t-1}=\tau^{*} \equiv h / n$, which makes the wage rate of care workers equal to that of firm workers. The equated wage rate is defined as $w_{t}^{*}$. The ratio of firm workers to the $t^{\text {th }}$ generation people is $l_{t}$; thus, the number of workers in the firm becomes $L_{t}=l_{t} N_{t}$. The number of care workers becomes $H_{t}=\left(1-l_{t}\right) N_{t}$. By using the total number of required long-term care workers, the ratio of firm workers becomes $l_{t}=1-\tau^{*}$.

The firm workers and care workers have the same utility function. For analytical convenience, we assume the utility function to be additively separable and logarithmic, as follows:

$$
U\left(c_{t}^{Y X}, c_{t+1}^{O X}\right)=a_{1} \ln \left(c_{t}^{Y X}\right)+a_{2} \ln \left(c_{t+1}^{O X}\right),
$$

Where $X=L$ or $H, a_{j}(j=1,2)$ are the utility weights of middle-age consumption $c_{t}^{Y X}$ and old-age consump-

${ }^{1}$ Of course, not all elderly people need support from eldercare workers. Some can support their own living, or manage with support from their families. On the other hand, others inevitably need the support of eldercare workers; whether or not this is the case depends on their health level. This study, however, does not consider the health level of each household, and simply assumes that an elderly representative household inevitably needs $h$ eldercare workers. 
tion $c_{t+1}^{O X}{ }^{1}$. We assume that $a_{j}>0$ and $a_{1}+a_{2}=1$.

The budget constraints become

$$
\begin{aligned}
\left(1-\tau_{t}-n b\right) w_{t}^{*} & =c_{t}^{Y X}+s_{t}^{X}, \\
\left(1+r_{t+1}\right) s_{t}^{X} & =c_{t+1}^{O X},
\end{aligned}
$$

where $b$ is the total cost of bearing a child, which includes the opportunity cost. Equation (2) expresses the situation of households whose disposable income is divided between consumption and savings, owing to middle age. Equation (3) expresses the situation of households that spend all their returns from savings on old-age consumption. Households choose savings so as to maximize their expected lifetime utility. The optimal savings becomes $s_{t}^{*}=a_{2}\left(1-\tau^{*}-n b\right) w_{t}^{*}$. Because the wage rate is the same between care workers and firm workers, the optimal savings also become identical. Using the optimal savings, the wage rate and the optimal savings become constant:

$$
\begin{gathered}
w^{*}=\alpha_{2}^{1 / \alpha_{2}}\left(a_{2} \varpi /\left(a_{1}+a_{2}\right)\right)^{\alpha_{1} / \alpha_{2}}, \\
s^{*}=a_{2}\left(1-\tau^{*}-n b\right) w^{*},
\end{gathered}
$$

where $\varpi \equiv\left(1-\tau^{*}-n b\right) /(n-h)$. By substituting Equations (4) and (5) into Equation (1), we derive the indirect utility function: $U\left(c^{Y^{*}}, c^{O^{*}}\right)=\left(a_{1}+a_{2} \alpha_{1}\right) \ln \left[\left(1-\tau^{*}-n b\right) w^{*}\right]+a_{2} \alpha_{2} \ln [n-h]+B$, where $B \equiv a_{1} \ln \left(a_{1}\right)+a_{2} \alpha_{1} \ln \left(a_{2}\right)-\left(a_{1}+a_{2} \alpha_{1}\right) \ln \left(a_{1}+a_{2}\right)$.

By differentiating Equation (4) with respect to $n$, we obtain

$$
\frac{\mathrm{d} w^{*}}{\mathrm{~d} n}=\frac{\left(b h-\left(1-\tau^{*}\right)^{2}\right)}{(n-h)\left(1-\tau^{*}-n b\right)} \frac{\alpha_{1}}{\alpha_{2}} w^{*} .
$$

Thus,

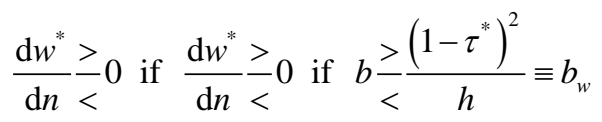

what is more, since $(1-b h)>0$, we have

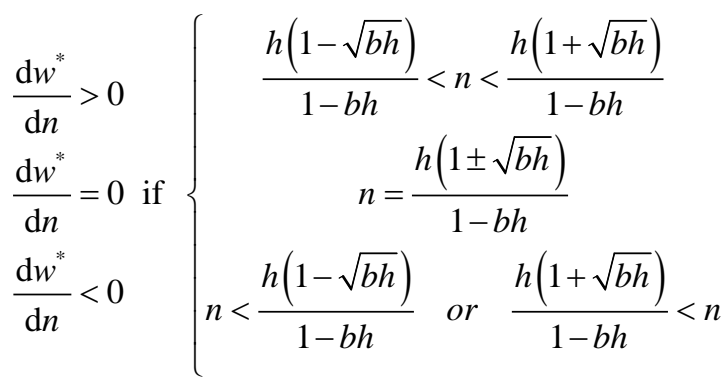

The condition of Equation (7a) implies that an increase in the number of children per household can increase the wage rate, if the opportunity-cost rate of bearing a child is sufficiently high.

Next, let us focus on the effects of an increase in the number of children on the household's steady-state utility level. These effects can be calculated by differentiating the indirect utility function with respect to $n$ :

$$
\frac{\mathrm{d} U\left(c^{Y^{*}}, c^{O^{*}}\right)}{\mathrm{d} n}=\frac{Q\left(\tau^{*} / n-b\right)}{\left(1-\tau^{*}-n b\right)}-\frac{q}{(n-h)},
$$

where $Q \equiv\left(a_{1}+a_{2} \alpha_{1}\right) / \alpha_{2}$ and $q \equiv\left(a_{1}+a_{2} \alpha_{1}\right)\left(\alpha_{1} / \alpha_{2}\right)-a_{2} \alpha_{2}$. Thus, 


$$
\frac{\mathrm{d} U\left(c^{Y^{*}}, c^{O^{*}}\right)}{\mathrm{d} n} \frac{>}{<} 0 \text { if } b \frac{}{<}\left(\frac{Q \tau^{*}-q}{Q\left(1-\tau^{*}\right)-q}\right)\left(\frac{1-\tau^{*}}{n}\right) \equiv b_{U}
$$

The condition of Equation (9) implies that an increase in a household's number of children can increase its utility level, if the opportunity-cost rate of bearing a child is sufficiently high; this implies children are relatively valuable.

A comparison of the condition of Equation (7a) with that of Equation (9) shows that:

$$
b_{U} \leq b_{w} \text { if } \tau^{*} \leq \frac{1}{>}
$$

because $Q>q$. The higher the care-tax rate becomes, the larger the number of required long-term care workers becomes. However, this number is not overly large; thus, the tax rate becomes less than one-half. Therefore, Equation (10) implies that an increase in the number of children tends to increase household utility without there being an increase in the steady-state wage rate, when the burden of care per capita is sufficiently small.

Let us now focus on the relationship between the number of children and household utility. The first term of the right-hand side of Equation (8) - which implies the effects of an increase in the number of children on the individual disposable income rate-becomes positive(negative) if the number of children is less(more) than $\sqrt{h / b}$. The second term on the right-hand side of Equation (8) - which implies the effects of an increase in the amount of labor-depends on the value of $q$. $q$ becomes either positive, negative, or zero; if $q$ is zero, which would imply that the effects of an increase in the number of labor are canceled out, the number of children $\sqrt{h / b}$ would maximize the utility level. If $q$ is positive(negative), which would imply that the effects of an increase in the amount of labor are negative(positive), the number of children needed to maximize the utility level become less(more) than $\sqrt{h / b}$. These relationships are described in Figure 2. In the case of $q>0$ $(q<0)$, the relationships are described in Figure 2(a), Figure 2(b).

The level of utility depends not only on the wage rate, but also on the disposal rate- the latter of which can be directly increased through a decrease in the burden of care that stems from an increase in the number of children. However, the wage rate can be only indirectly increased by an increase in the disposal rate that stems from an increase in the number of children. Thus, while an increase in the number of children tends to reduce the wage rate, it also tends to increase the utility.

The variables are given as reasonable parameters, and we explicitly present the situation in Japan. We present in Table 1 the values of the main exogenous parameters of the model. One period in this model is converted to a 25-year span. The preference ratio between consumption in the working period and consumption in the retirement period is adjusted to be summed to 1.0 , and the annual time preference corresponds to approximately $1.0 \%^{2}$. The necessary number of long-term care workers per person aged 65 and over in 2007 became about 0.01 , according to the Ministry of Health, Labor and Welfare's Survey of Institutions and Establishments for Long-term Care and the Ministry of Internal Affairs and Communications' National Census. The capital share rate of the production function is based on the capital distribution rate, which is acquired from data in the Cabinet Office's Annual Report on National Accounts for 2003. The National Institute of Population and Social Security Research estimates that Japan's 2012 total fertility rate (i.e., average number of children each woman has in her lifetime) was about 1.41.

According to the exogenous variables in Table 1, we put together the endogenously calculated variables of this model (Table 2). As a result, we derive $b_{U}(=0.02)<b_{w}(=98.59)$. According to the "White Paper on the National Lifestyle" (2007), the cost of raising a child is JPY13.02 million, and the additional costs of a second child are JPY10.52 million. The cost of raising 1.41 children is directly calculated as a weighted average: JPY12.00 million. The opportunity cost of raising children is JPY227.32 million $^{3}$. In this case, the total direct and indirect cost of raising children becomes JPY239.32 million, which represents $27.42 \%$ per child of a household's total income (male university graduates: JPY342.60 million; female university graduates: JPY276.45 million) (“Basic Survey on Wage Structure," 2003). This implies $b=0.27$.

\footnotetext{
${ }^{2}$ Hereafter, the superscript $Y(O)$ represents middle (old) age. The superscript $L(H)$ denotes the variables relating to firm (care) workers. The variables with the subscript $t$ belong to period $t$.

${ }^{3}$ When calculating these time-preference variables, we reference the study of Yanagihara and Kato [10], who analyze the pension system in Japan by using an overlapping two-generation model. In that model, the discount rate on second-period consumption is assumed to be 0.85 .
} 


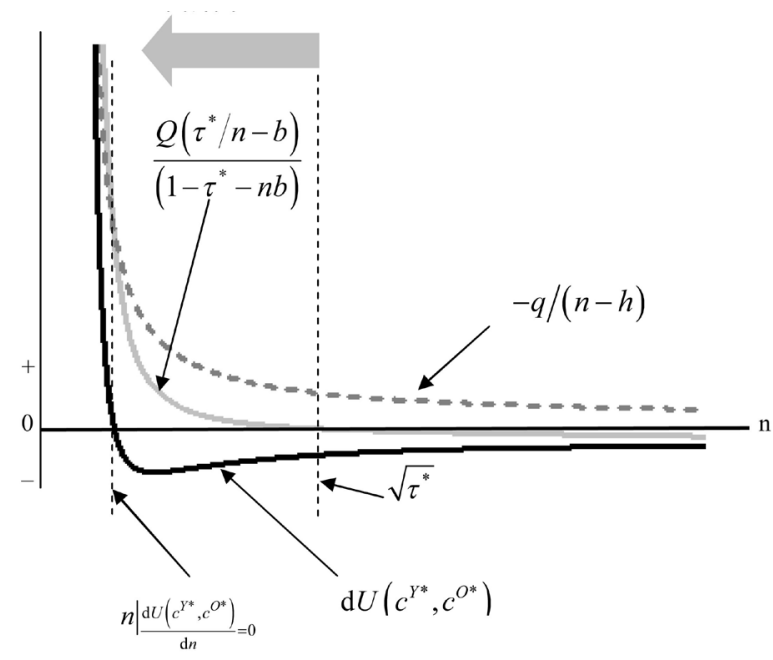

(a)

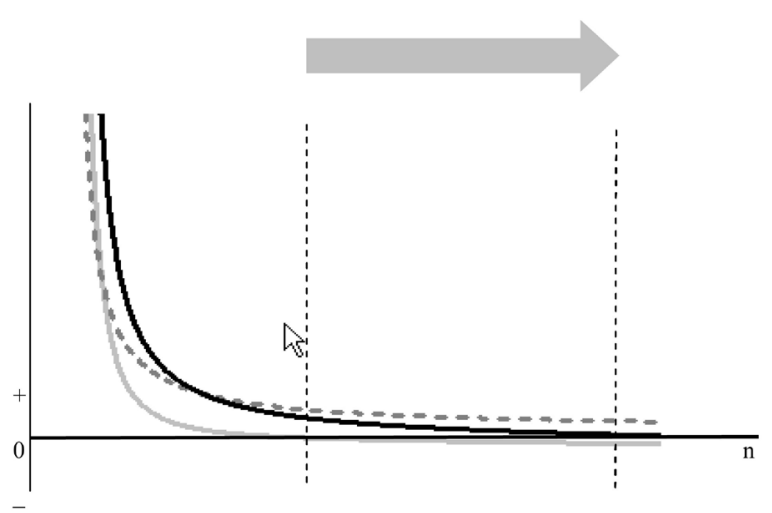

(b)

Figure 2. (a) The case of $q>0$; (b) The case of $q<0$.

Table 1. Exogenous model variables.

\begin{tabular}{rc} 
Exogenous Variable & Value \\
\hline Preference to consume in the working period $\left(a_{1}\right)$ & 0.54 \\
Preference to consume in the retirement period $\left(a_{2}\right)$ & 0.46 \\
Capital share rate $\left(\alpha_{1}\right)$ & 0.3 \\
Labor share rate $\left(\alpha_{2}\right)$ & 0.7 \\
Number of children per household & 1.29 \\
Necessary number of long-term care workers per surviving elderly persons & 0.04
\end{tabular}

Table 2. Calculated model variables.

\begin{tabular}{cccc}
\hline & Variable & Value \\
\hline$\tau^{*}$ & $Q$ & 0.03 & 0.97 \\
-0.03 & 23.47 \\
$b_{w}$ & $q$ & 0.05 \\
\hline
\end{tabular}

A comparison of the values of $b_{U}, b_{w}$, and $b$ shows that an improvement in the fertility rate reduces the wage rate, but also increases house hold utility. A numerical example where the values are set to accord with the Japanese situation implies that the government should support households in having more children, by offering subsidies or in other ways, so as to ease the burden placed on the working generation of funding long-term care services.

It is generally accepted that in Japan, the demand for long-term care workers will drastically increase in the future. If the necessary number of long-term care workers per person aged 65 were to increase to 0.1, we would have $b_{U}(=0.07)<b_{w}(=8.63)$. Even if the necessary number of long-term care workers per person were to grown 10-fold relative to present figures, an improvement in the fertility rate would definitely increase the utility level but nonetheless reduce the wage rate, assuming that the cost of raising children remains the same as that at present $(b=0.27)$. The results of these analyses imply that the demand for children who will ease the burden of caring for elderly generations is very large, especially when one considers the fact that elderly people consume only or relatively more labor-intensive services. 


\section{Conclusions and Remaining Issues}

In this study, we analyzed the effects of an increase in the number of children on an economy where having a sufficient number of care workers is ensured. An increase in the number of children can reduce the wage rate but increase household utility, even if the burden per capita of caring for the elderly was sufficiently small. A numerical example for the case of Japan was also calculated; that example implied that the government should support households in having more children - through the provision of subsidies or other supports-so as to ease the burden of long-term care services provision that is placed on the working generation. This applies not only to long-term care services, but also to the pressures being placed on public pension plans (e.g., Groezen, Leers, and Meijdam [11]).

To analyze the effects of an increase in the number of children on household utility when only the minimum necessary long-term care services are produced, we examine the exogenously given number of children per person. Under normal conditions, however, the number of children per person is a household choice variable; as such, it is not exogenously given. Thus, we should consider a model where a household endogenously choose sits number of children, and the government supports it through child allowances or similar instruments; under such conditions, households could increase their number of children, if they so desired.

\section{Acknowledgements}

Financial support for this study was provided through a Grant-in-Aid for Scientific Research (No. 25380370). The author is grateful to Professor Hirobumi Akagi (Meijyo University) for helpful comments. Any remaining errors are the author's responsibility.

\section{References}

[1] Groezen, B.V., Meijdam, L. and Verbon, H.A.A. (2005) Serving the Old: Ageing and Economic Growth. Oxford University Press, 57, 647-663.

[2] Groezen, B.V., Meijdam, L. and Verbon, H.A.A. (2007) Increased Pension Savings: Blessing or Curse? Social Security Reform in a Two-Sector Growth Model. Economica, 74, 736-755. http://dx.doi.org/10.1111/j.1468-0335.2006.00557.x

[3] Groezen, B.V., Meijdam, L. and Verbon, H.A.A. (2007) The Case for Pay-as-You-Go Pensions in a Service Economy. Scottish Journal of Political Economy, 54, 151-165. http://dx.doi.org/10.1111/j.1467-9485.2007.00409.x

[4] Sandmo, A. (1990) Tax Distortions and Household Production. Oxford Economic Papers, 42, 78-90.

[5] Kleven, H.J., Richter, W.F. and Sorensen, P.B. (2000) Optimal Taxation with Household Production. Oxford Economic Papers, 52, 584-594. http://dx.doi.org/10.1093/oep/52.3.584

[6] Yoshida, M. and Yuki, K. (2004) Optimal Taxation of Elderly Care Services. The Japanese Economic Review, 55, 86-100. http://dx.doi.org/10.1111/j.1468-5876.2004.00295.x

[7] Samuelson, P.A. (1958) An Exact Consumption-Loan Model of Interest with or without the Social Contrivance of Money. Journal of Political Economy, 66, 467-482. http://dx.doi.org/10.1086/258100

[8] Galasso, V. and Profeta, P. (2004) Lessons for an Aging Society: The Political Sustainability of Social Security Systems. Economic Policy, 19, 63-115. http://dx.doi.org/10.1111/j.1468-0327.2004.00119.x

[9] Bethencourt, C. and Galasso, V. (2008) Political Complements in the Welfare State: Health Care and Social Security. Journal of Public Economics, 92, 609-632. http://dx.doi.org/10.1016/j.jpubeco.2007.06.005

[10] Yanagihara, M. and Kato, H. (2006) Nihon Niokeru Hukahoushiki Nenkin no Dogakubunseki-Kojin no Rodo Shotoku-zei no datsuzeigakanounabaai. Kaikeikensa-Kenkyu, 33, 71-88.

[11] Groezen, B.V., Leers, T. and Meijdam, L. (2003) Social Security and Endogenous Fertility: Pensions and Child Allowances as Siamese Twins. Journal of Public Economics, 87, 233-251. http://dx.doi.org/10.1016/S0047-2727(01)00134-7 